\title{
A Quasi Experiment to Implement Multimodal Strategy to Improve Hand Hygiene Behavior in a Healthcare Facility in Central Saudi Arabia
}

\author{
Ashraf E. Saad1, Al-Wasila T. Al-Natig2, Mostafa M. Sadek ${ }^{3,4}$, Raouf M. Afifi ${ }^{5,6 *}$ \\ ${ }^{1}$ Department of Preventive Medicine, Armed Forces Hospital at Wadi Al-Dawasir, Riyadh, KSA \\ ${ }^{2}$ Infection Prevention and Control Unit, Armed Forces Hospital at Wadi Al-Dawsir, Riyadh, KSA \\ ${ }^{3}$ Sadeklab Laboratories, Alexandria, Egypt \\ ${ }^{4}$ Formly, Microbiology and Public Health Department, Military Medical Academy, Alexandria, Egypt \\ ${ }^{5}$ Community Health Research Institute, International Management-Health Services, Indianapolis, IN, USA \\ ${ }^{6}$ Health Research Institute, SA Consultancy and Training, Cairo, Egypt \\ Email: ^raoufafifi@hotmail.com
}

How to cite this paper: Saad, A.E., AlNatig, A.-W.T., Sadek, M.M. and Afifi, R.M. (2019) A Quasi Experiment to Implement Multimodal Strategy to Improve Hand Hygiene Behavior in a Healthcare Facility in Central Saudi Arabia. Advances in Infectious Diseases, 9, 49-63.

https://doi.org/10.4236/aid.2019.91005

Received: January 24, 2019

Accepted: March 24, 2019

Published: March 27, 2019

Copyright $\odot 2019$ by author(s) and Scientific Research Publishing Inc. This work is licensed under the Creative Commons Attribution International License (CC BY 4.0).

http://creativecommons.org/licenses/by/4.0/

\begin{abstract}
Background: Hand hygiene (HH) compliance of healthcare workers (HCWs) remains suboptimal despite standard multimodal promotion, and evidence for the effectiveness of novel interventions is urgently needed. Aim: Improve HCWs' HH compliance toward minimizing healthcare associated infection (HCAI) risk in Wadi Al Dawasir Hospital (WDH), central Kingdom of Saudi Arabia (KSA). Methodology: A quasi experimental approach was adopted to achieve study aim. The HCWs' behavior of $\mathrm{HH}$ during the duration between 2015 and 2016 was evaluated before and after a $\mathrm{HH}$ educational plan based on the World Health Organization (WHO) "Multimodal HH Improvement Strategy" (MMHHIS). The HCWs' compliance in response to HH indications represented by the WHO's "My 5-Moments for HH" and the type of HH action taken, whether hand washing (HW) or hand-rubbing (HR) were analyzed. Results: The number of opportunities observed of $\mathrm{HH}$ performance accounted 230 in 2015 (pre-education), and 237 in 2016 (post-education). The HCWs' HH compliance rate in the pre-education phase did not vary by the 5-moment indications $\left[\chi^{2}(\mathrm{df} 4)=0.01, p=0.98\right]$. Conversely, the compliance rate after $\mathrm{HH}$ education was higher than non-compliance across all 5 -moment indication opportunities (ranged between $57.0 \%$ up to $88.9 \%$ ) $\left[\chi^{2}(\mathrm{df} 1)=18.25, p<0.001\right]$. Only the $3^{\text {rd }}$ and $4^{\text {th }} 5$-moment indications ("after body fluid exposure" and "after patient contact," respectively) were met with a significant HH improvement $\left[\chi^{2}(\mathrm{df} 1)=8.98, p=0.003\right.$; and $\chi^{2}(\mathrm{df} 1)=16.3$, $p<0.0001$, respectively]. An overall improvement of $\mathrm{HH}$ compliance from $49.1 \%$ to $69.6 \%$ was significantly achieved as a result of submission to the se-
\end{abstract}


lected $\mathrm{HH}$ educational plan $(\mathrm{Z}=-4.38, p=0.001)$. Only physicians and nurses showed a significant "within-profession" improvement in $\mathrm{HH}$ compliance after education, compared to that before education $(\mathrm{Z}=-3.51, p=$ $0.001, \mathrm{Z}=-2.48, p=0.013$, respectively). Conclusions: Applying a $\mathrm{HH}$ education plan based on standardized multimodal $\mathrm{HH}$ strategy proved effective in improving the $\mathrm{HH}$ compliance of the hospital's staff. An ongoing observation policy within a $\mathrm{HH}$-resourceful environment assures a sustainable and sound HCWs' HH behavior.

\section{Keywords}

Quasi Experiment, Multimodal Strategy, Hand Hygiene, Healthcare Facility, Central Saudi Arabia

\section{Introduction}

Patient safety involves a multitude of preventive standards and procedures to mitigate a myriad of risks and harmful effects upon the patients in healthcare facilities. Cross-infection at a healthcare facility, known as healthcare-associated infection (HCAI), occurs as a result of transmission of infectious agents during the course of care seeking for other conditions [1]. Largely, HCAI stands as a major safety issue, with severe and greatly underestimated effect on patients and the healthcare systems [2] [3] [4] [5]. In developed countries, the prevalence of HCAI is estimated between $5.1 \%$ and $11.6 \%$. However, most reports of HCAI prevalence from developing countries are also above $10 \%$. Especially riskier patients and those whose immune status is jeopardized, as in intensive care units (ICUs), neonatal ICUs (NICUs), surgical wards, and long-term care facilities (LTCU), are at a higher risk for HCAI with all the devastating health consequences [6]. The HCWs' hands have been known to be the main culprit of cross-transmission of pathogens across health facilities by touching the environment or patients' skin during care delivery [7] [8]. The mechanisms through which HCAI may be transmitted support that $\mathrm{HH}$ is a critical component of a bundle approaches for preventing and controlling HCAIs. The major obstacle against less risky HCAI environment is still attributed to an inconvenient $\mathrm{HH}$ compliance by the HCWs. Studies have reported as low less than $40 \% \mathrm{HH}$ compliance among HCWs globally [9] [10] [11]. Lack of HH education, being a physician, working in ICUs, lack of resources for adequate $\mathrm{HH}$, including $\mathrm{HH}$ agents and skin care products, and lack of $\mathrm{HH}$ performance feedback, all stand behind the high HH non-compliance trend of HCWs [10] [12] [13] [14].

The WHO First Global Patient Safety Challenge: "Clean Care is Safer Care" is an initiative aiming to strengthen international commitment to address HCAI [15]. The initiative brings together the newly developed "WHO Guidelines on $\mathrm{HH}$ in Healthcare" through implementation of the WHO multi-modal $\mathrm{HH}$ strategy in the $2009 \mathrm{HH}$ technical reference manual [16]. The guidelines create a 
unified description for $\mathrm{HH}$ methods, indications and right moments; observation process [17] [18]. The multimodal strategy encompasses conceptual and procedural elements, including: 1) system change to ensure access of HCWs to $\mathrm{HH}$ facilities with emphasis on availability of alcohol-based hand rub (ABHR) formulations at the point of care, 2) ongoing $\mathrm{HH}$ training and education, 3) evaluation of practices and feedback, 4) reminders at the workplace, and 5) providing a climate of safety through institution [16]. In practice, the WHO is determining the 5-moments for $\mathrm{HH}$ concept which defines key moments when HCWs should perform $\mathrm{HH}$ [19]. The 5-moment $\mathrm{HH}$ approach recommends HCWs to clean their hands, 1) before patient contact, 2) before aseptic procedure, 3) after body fluid exposure risk, 4) after patient contact, and 5) after contact with patient surroundings, as $\mathrm{HH}$ indications. Importantly, it has been demonstrated that the implementation of the entire WHO multimodal strategy is quite feasible and effective in enhancing $\mathrm{HH}$ compliance and the eventual reduction of HCAI [20] [21] [22] [23].

In the Saudi Arabian healthcare arena, there have been some studies presenting some data on HH improvement. However, most of these studies were centered on specific points of care, such as the ICU [13] [24] [25] and cardiac center [26]. A hospital-wide experiment in Makkah, west Saudi Arabia by Bukhari, et al. (2011) could evaluate the HH behavior among Hera hospital HCWs in most of the hospital's clinical departments [27]. We initiated this study for the implementation of WHO multimodal strategy in order to improve WDH staff awareness, compliance and correctness of $\mathrm{HH}$ practice, a step on the road to reduce HCAI and associated risks throughout WDH service environment. Accordingly, our goal was set as to continuously improve our HCWs' HH, aiming minimally for benchmark level of $\mathrm{HH}$ compliance of $70 \%$ during the first year after the education plan, with a target of $100 \%$ compliance.

\section{Methodology}

Wadi Al Dawasir Hospital (100 beds), is a secondary care facility with a number of subspecialties, catering for military personnel and their families. The hospital lies at Al-Dawasir valley in Najd desert within the jurisdiction of the Riyadh region, central KSA. The hospital includes over twelve standard clinical services and equipped with modern technologies. The preventive medicine department of WDH conducted a project to improve the HCWs' $\mathrm{HH}$ attitude among the hospital's efforts to prevent HCAI and bringing its rates to lowermost. The project extended from 2015 through 2016. The project's strategy encompassed four steps, first to identify the hospital's preparedness for sound HH trend, second to carry on baseline observation of the HCWs' HH practice, third to implement a predesigned $\mathrm{HH}$ intervention plan and then evaluate the $\mathrm{HCWs} \mathrm{HH}$ behavior and compliance after the intervention, fourth to assure sound and sustainable $\mathrm{HH}$ culture through continued follow-up and evaluation of the experiment. In preparing for the project, financial resources to furnish basic $\mathrm{HH}$ prac- 
tice requirements were forecasted, and project's aim was related to the hospital's authority. The number and distribution of HW sinks were reviewed (one sink for each room with two beds and one sink in each isolation room), which were further equipped with un-medicated soap and paper towels. Also ABHR dispensers were located, one inside each inpatient room, one outside each room, one in each medication trolley, as well as all other points of care. All of the hospital's medical staff, including physicians, nurses, care providing technicians/ auxiliary staff in the departments and outpatient service, including male, female, and pediatric wards, NICU, ICU, dental clinic, and emergency room (ER); were eligible to join the project. We implemented the WHO multimodal strategy and assessed staff's $\mathrm{HH}$ compliance before and after the interventions. Compliance was defined as the proportion of predefined opportunities met by $\mathrm{HH}$ actions (HW or HR) [17]. All five principal conceptual and procedural elements of the strategy [16] were emphasized in planning and implementing our project. The project's team encompassed two qualified infection control nurses and an infection control practitioner. In the first phase of the project (pre-intervention, 2015) we aimed to identify and observe the hospital staffs $\mathrm{HH}$ behavior and compliance trend. Observation included applying the WHO's direct observation method [17] using specified WHO observation form for reporting HH behavioral components. The WHO observation method is based on the 5-moments for HH indications [19]. The observation plan was based on recording the following information: 1) the indication for $\mathrm{HH}$ performance in accordance with the 5-moment $\mathrm{HH}$ opportunities, 2) compliance, whether or not $\mathrm{HH}$ was performed and 3) action, whether HW or HR or technique was done and the HH technique correctness. An "opportunity" for HH would be defined as the time HH should happen and it must relate to at least one HH indication (e.g., either of 5-moment of $\mathrm{HH})$. Likewise, $\mathrm{HH}$ compliance was calculated by dividing the number of observed $\mathrm{HH}$ moments where proper $\mathrm{HH}$ was practiced by the total number of observed HH moments multiplying by 100 [28]. Hand hygiene practice of the HCWs was monitored during the daily infection control team rounds across the hospital's clinical departments. The HCWs' HH practice was observed in $30-45$ minute sessions; no more than two HCWs would be monitored simultaneously, to assure a focused observation. In the event of the presence of time shortage of session, a limited number of HCWs in the same point of care were observed. During care sequences, the observation team was recording $\mathrm{HH}$ opportunities; either a positive or negative $\mathrm{HH}$ action would be recorded provided that it related to an indication [17]. Also during infection control rounds, if we noticed any staff with a wrongful $\mathrm{HH}$ practice or a low compliance, an immediate corrective training would be given on how to hygiene the hand. The second phase in 2016 started by an intensive HH education plan was conducted in the first 3 months (January through March) and was continued throughout the year. First we held an introductory workshop to all staff with participation from the hospital leaders to show the commitment. Another one-day formal training session 
was performed for each department. In training, there was an emphasis on ICUs due to the critical nature of these units, and the presence of reportedly lower $\mathrm{HH}$ compliance rates [11] [29]. Retraining was offered throughout this phase. For instance, we took the opportunity of relevant infection prevention activities, such as the international HH day, Middle East Respiratory Syndrome coronavirus (MERS CoV) symposium, and "international patient safety goals (IPSG) workshop. Educated material included power point slides, WHO-sample video clips, printed $\mathrm{WHO}-$ five moments, and $\mathrm{HH}$ technique demonstration, and small group discussion. Important points from the WHO's $\mathrm{HH}$ technical reference manual on $\mathrm{HH}$ practice of HCWs at different clinical healthcare settings were also taught [17]. In order to keep up with the training plan and furnish HH-oriented environment in the hospital, reminders, including roll-up stands and posters with $\mathrm{HH}$-promotion signs, as well as posters exhibiting the 5-moments for $\mathrm{HH}$, correct $\mathrm{HW}$ and $\mathrm{HR}$ techniques, and the role of $\mathrm{HH}$ in preventing HCAI messages were displayed. The posted materials were placed in visible places in all points of care. The messages were changed almost on monthly basis. Each department was receiving feedback on their HH performance. During the sessions, participating HCWs were being asked to demonstrate what they have learned regarding $\mathrm{HW} / \mathrm{HR}$ technique and the WHO 5-moments for HH. By the end of initial 3 months of training, all trained HCWs were considered eligible for attending to $\mathrm{HH}$ competency assessment; those who pass the assessment received a certificate with 1-year validity (to link to the employee's annual performance report). Two observation rounds were only carried in a day by each observer. In the wards, observing for $\mathrm{HH}$ actions was mostly performed at medication time, in order to save time and tackle a greater number of opportunities, (often, HCWs were mostly aware that they were monitored since they knew the infection control observation team members). In the post-education phase, there was no performance feedback during the observation rounds. All collected HH observation data were anonymous and confidential. It was difficult to tell how many times each HCW was observed during the project's life, for the same HCW most probably observed several times throughout the experiment's duration, and also that he or she would be engaged in several indications at a time. Instead, and based on the study's strategy, the type and number of opportunities were observed, during which the staff's $\mathrm{HH}$ compliance and action were recorded.

Study variables: The study's independent variables include the HCWs' and hospital's categorical data, such as profession, specialty, department/unit, as well as the inputs encompassed within the WHO's observation method, including the 5 -moments for $\mathrm{HH}$ indications (before patient contact and aseptic procedure, and after body fluid exposure, patient contact and the surroundings). The principal dependent study variable was represented by the HCWs' compliance $(\mathrm{HH}$ "done"/"not done") with HH indications, and the secondary outcome variable was the action, which involves the type of $\mathrm{HH}$ response performed, whether HW 
or HR. The study's outcomes would be analyzed before the educational plan (2015) and after education (2016). Since the study's philosophy was based on promoting for adopting $\mathrm{HH}$ by the HCWs as a hygienic behavior and a professional work style, and examining how $\mathrm{HH}$ training would improve such behavior, all HCWs were taken as quasi study subjects; no control group. We needed all HCWs to benefit from the experiment timely.

Statistical analysis. The collected data were entered to MS program with adequate back up, and observations made ready for statistical analysis. First, descriptive statistics, including frequency data, were displayed. The study's quantitative data were summarized as count (\%). Analytical statistics mainly includes nonparametric techniques (NPMT). For instance, testing $\mathrm{HH}$ compliance pattern of the HCWs in response to the 5-moments for $\mathrm{HH}$ indications either in the pre-education phase or in the post-education phase, chi-square tests could be used. Measuring the difference in HH compliance before and after education, a repeated measure technique, such as the Wilcoxon signed ranks test, for related samples could be used. Also Wilcoxon signed ranks test could be used to measure the change in $\mathrm{HH}$ compliance within departments as well as within profession groups; (often, only chi-square test could be applied to measure HH compliance changes in case of unsatisfactory post-education data and corresponding pre-education compliance state (as in analyzing $\mathrm{HH}$ responses during individual 5 moment indications) to run repeated measure tests. Measuring the difference in compliance between professions or between departments, and also the type of $\mathrm{H}$ action (HW/HR), chi-square test (or Fisher's exact, where appropriate) could be used. The SPSS (Chicago, IL) software-version-20 was used for statistical analyses. Our level for tolerating type- 1 error would be $\alpha=0.05$, and results with $p$-value $<0.05$ were considered statistically significant. A clearance from WDH Research Ethics Committee to commence the study was granted.

\section{Results}

As in Table 1, the HCWs' HH compliance trend before the HH education did not significantly vary by the 5-moments for $\mathrm{HH}$ indications. In 230 observed opportunities for a $\mathrm{HH}$ practice in the pre-education era, only $113(49.1 \%) \mathrm{HH}$ actions were done. The frequency $\mathrm{HH}$ was done and that $\mathrm{HH}$ was not done were almost equal (around 49.3\% - 50.9\%, both actions) [ $\chi^{2}(\mathrm{df} 4)=0.01, \mathrm{p}=0.98$ ].

The total of opportunities for $\mathrm{HH}$ practice accounted 230. Hand-rubbing was done more frequency than HW (57.5\% vs. $42.5 \%$ ), however such difference was not statistically significantly (Fisher's exact, $\mathrm{p}=0.39$, Table 1 footnote).

As in Table 2(a), only the changes in the HCWs' HH compliance before and after $\mathrm{HH}$ education in response to "after body fluid exposure" (from $50 \%$ to 88.9\%) - and that "after patient contact" moment indications (from $50.9 \%$ to $84.7 \%)$ were statistically significant $\left[\chi^{2}(\mathrm{df} 1)=8.98, p=0.003\right.$, and $\chi^{2}(\mathrm{df} 1)=$ $16.3, p<0.0001$, respectively].

In Table 2(b), $\mathrm{HH}$ compliance trend of the HCWs' after $\mathrm{HH}$ education varied 
by the variation in $\mathrm{HH}$ 5-moment indications. The frequency $\mathrm{HH}$ was done was consistently higher than that $\mathrm{HH}$ was not done. Out of 237 opportunities for a $\mathrm{HH}$ practice observed in the post-education era, 165 (69.6\%) $\mathrm{HH}$ actions were done. Positive $\mathrm{HH}$ action was done most frequently after exposure to body fluids (88.9\%), followed by that after patient contact $(84.7 \%)$, while those before patient contact, before clean/aseptic procedure, and after contact with patient surroundings mounted $57.0 \%, 63.7 \%$ and $63.9 \%$ respectively $)\left[\chi^{2}(\mathrm{df} 4)=18.25, p=\right.$ 0.001]. Hand-rubbing was significantly practiced more frequently than HW (58.2\% vs. $41.8 \%$ (Fisher's exact $=13.1, p<0.0001)$, (Table 2 footnote).

The overall HCWs' $\mathrm{HH}$ compliance rate after the education plan completion was significantly higher than the one prior to education $(Z=-4.38, p<0.001)$, (Table 3).

Table 4 displays the change in $\mathrm{HH}$ compliance within profession groups. Physicians and nurses were able to improve their $\mathrm{HH}$ compliance (+ve ranks significantly $>-$ ve ranks $),(Z=-3.51, p<0.0001 ; Z=-2.48, p=0.013$, respectively), but not the technicians/auxiliary staff $(\mathrm{Z}=-1.0, p=0.32)$.

The variation in $\mathrm{HH}$ compliance between professions after $\mathrm{HH}$ education was not statistically significant, [nurses and physicians showed an almost equal $\mathrm{HH}$ compliance rate: $70.3 \%, 69.9 \%$, respectively, technicians/auxiliary staff least compliant $(62.2 \%)],\left[\chi^{2}(\mathrm{df} 2)=0.41, p=0.81\right]$.

The variation in $\mathrm{HH}$ compliance between departments/units after $\mathrm{HH}$ education was statistically significant, $\left[\chi^{2}(\mathrm{df} 6)=18.76, p=0.005\right]$, (Table 5(b)): female ward recorded maximum compliance rate $(81.8 \%)$, followed by NICU (80.8\%), male ward (78.7\%), dental clinic (72.7\%), and pediatric ward (62.5\%). The compliance rate in the ICU and ER department was least observed $(57.1 \%$, $41.7 \%$, respectively), (Table $5(\mathrm{~b})$ ).

Table 1. Pre-education HCW HH compliance by the 5-moment indications (2015).

\begin{tabular}{|c|c|c|c|c|c|}
\hline \multicolumn{6}{|c|}{ HH compliance: pre-education } \\
\hline \multirow{2}{*}{ Indication } & \multirow{2}{*}{$\begin{array}{l}\text { Done }^{*} \\
\mathrm{n}(\%)\end{array}$} & \multicolumn{2}{|l|}{ Not done } & \multirow{2}{*}{ Test statistic } & \multirow{2}{*}{$p$-value } \\
\hline & & n (\%) & Total(\%) & & \\
\hline $\begin{array}{c}\text { Before } \\
\text { patient contact }\end{array}$ & $33(49.3)$ & $34(50.7)$ & $67(100.0)$ & & \\
\hline $\begin{array}{c}\text { Before clean/aseptic } \\
\text { procedure }\end{array}$ & $9(50.0)$ & $9(50.0)$ & $18(100.0)$ & & \\
\hline $\begin{array}{l}\text { After body fluid } \\
\text { exposure }\end{array}$ & $11(50.0)$ & $11(50.0)$ & $22(100.0)$ & $\chi^{2}(\mathrm{df} 4)=0.01$ & 0.98 \\
\hline $\begin{array}{c}\text { After } \\
\text { patient contact }\end{array}$ & $26(50.9)$ & $27(49.1)$ & $53(100.0)$ & & \\
\hline $\begin{array}{l}\text { After contact with } \\
\text { patient surroundings }\end{array}$ & $33(49.3)$ & $34(50.7)$ & $67(100.0)$ & & \\
\hline Total & $113(49.1)$ & $117(50.9)$ & $230100.0)$ & & \\
\hline
\end{tabular}

*[HW: 48/113 (42.5\%); HR: 65/113 (57.5\%); Fisher's exact, $p=0.39]$. 
Table 2. (a) Pre- vs. post-education compliance within each of the 5-moment indications; (b) Post-education HCW HH compliance by the 5 -moment indications (2016).

(a)

\begin{tabular}{|c|c|c|c|c|c|c|c|c|}
\hline \multirow{3}{*}{ Indication } & \multicolumn{3}{|c|}{ HH compliance: pre-education } & \multicolumn{3}{|c|}{ HH compliance: post-education } & \multirow{3}{*}{ Test statistic } & \multirow{3}{*}{$p$-value } \\
\hline & Done & Not done & \multirow{2}{*}{$\begin{array}{l}\text { Total } \\
(\%)\end{array}$} & Done & Not done & Total & & \\
\hline & $\mathrm{n}(\%)$ & $\mathrm{n}(\%)$ & & n (\%) & $\mathrm{n}(\%)$ & (\%) & & \\
\hline $\begin{array}{c}\text { Before } \\
\text { patient contact }\end{array}$ & $33(49.3)$ & $\begin{array}{c}34 \\
(50.7)\end{array}$ & $\begin{array}{c}67 \\
(100.0)\end{array}$ & $\begin{array}{c}45 \\
(57.0)\end{array}$ & $\begin{array}{c}34 \\
(43.0)\end{array}$ & $79(100.0)$ & $\begin{array}{l}\chi^{2}(\mathrm{df} 1) \\
=0.86\end{array}$ & 0.35 \\
\hline $\begin{array}{c}\text { Before clean/aseptic } \\
\text { procedure }\end{array}$ & $\begin{array}{c}9 \\
(50.0)\end{array}$ & $\begin{array}{c}9 \\
(50.0)\end{array}$ & $18(100.0)$ & $\begin{array}{c}7 \\
(63.7)\end{array}$ & $\begin{array}{c}4 \\
(36.4)\end{array}$ & $11(100.0)$ & $\begin{array}{l}\chi^{2}(\mathrm{df} 1) \\
=0.51\end{array}$ & 0.47 \\
\hline $\begin{array}{l}\text { After body } \\
\text { fluid exposure }\end{array}$ & $11(50.0)$ & $\begin{array}{c}11 \\
(50.0)\end{array}$ & $22(100.0)$ & $24(88.9)$ & $\begin{array}{c}3 \\
(11.1)\end{array}$ & $27(100.0)$ & $\begin{array}{l}\chi^{2}(\mathrm{df} 1) \\
=8.98\end{array}$ & 0.003 \\
\hline $\begin{array}{c}\text { After } \\
\text { patient contact }\end{array}$ & $26(50.9)$ & $\begin{array}{c}27 \\
(49.1)\end{array}$ & $53(100.0)$ & $50(84.7)$ & $\begin{array}{c}9 \\
(15.3)\end{array}$ & $59(100.0)$ & $\begin{array}{l}\chi^{2}(\mathrm{df} 1) \\
=16.3\end{array}$ & $<0.0001$ \\
\hline $\begin{array}{l}\text { After contact with } \\
\text { patient surroundings }\end{array}$ & $33(49.3)$ & $\begin{array}{c}34 \\
(50.7)\end{array}$ & $67(100.0)$ & $39(63.9)$ & $\begin{array}{c}22 \\
(36.1)\end{array}$ & $61(100.0)$ & $\begin{array}{l}\chi^{2}(\mathrm{df} 1) \\
=2.8\end{array}$ & 0.09 \\
\hline Total & $113(49.1)$ & $\begin{array}{c}117 \\
(50.9)\end{array}$ & $230100.0)$ & $165(69.6)$ & $\begin{array}{c}72 \\
(30.4)\end{array}$ & $237100.0)$ & & \\
\hline
\end{tabular}

(b)

\begin{tabular}{|c|c|c|c|c|c|}
\hline \multicolumn{6}{|c|}{ HH compliance: post-education } \\
\hline \multirow{2}{*}{ Indication } & Done $e^{*}$ & Not done & \multirow{2}{*}{ Total (\%) } & \multirow{2}{*}{ Test statistic } & \multirow{2}{*}{$p$-value } \\
\hline & $\mathrm{n}(\%)$ & n (\%) & & & \\
\hline $\begin{array}{c}\text { Before } \\
\text { patient contact }\end{array}$ & $45(57.0)$ & $34(43.0)$ & $79(100.0)$ & \multirow{6}{*}{$\chi^{2}(\mathrm{df} 4)=18.25$} & \multirow{6}{*}{0.001} \\
\hline $\begin{array}{c}\text { Before clean/aseptic } \\
\text { procedure }\end{array}$ & $7(63.7)$ & $4(36.4)$ & $11(100.0)$ & & \\
\hline $\begin{array}{c}\text { After body } \\
\text { fluid exposure }\end{array}$ & $24(88.9)$ & $3(11.1)$ & $27(100.0)$ & & \\
\hline $\begin{array}{c}\text { After } \\
\text { patient contact }\end{array}$ & $50(84.7)$ & $9(15.3)$ & $59(100.0)$ & & \\
\hline $\begin{array}{l}\text { After contact with } \\
\text { patient surroundings }\end{array}$ & $39(63.9)$ & $22(36.1)$ & $61(100.0)$ & & \\
\hline Total & $165(69.6)$ & $72(30.4)$ & $237100.0)$ & & \\
\hline
\end{tabular}

*[HW: 69/165 (41.8\%), HR: 96/165 (58.2); Fisher's exact 13.1, $p<0.0001]$.

Table 3. Healthcare workers' HH compliance during the experiment's duration (Wilcoxon signed ranks—related samples test).

\begin{tabular}{|c|c|c|c|c|c|c|}
\hline \multicolumn{7}{|c|}{ Rank } \\
\hline Compliance & & $\mathrm{n}$ & Mean & Sum & Test statistic & $p$-value \\
\hline & +ve ranks & $81^{\mathrm{b}}$ & 58.0 & 4698.0 & & \\
\hline & -ve ranks & $34^{\mathrm{a}}$ & 58.0 & 1972.0 & & \\
\hline \multirow[t]{2}{*}{ Pre-education-post-education } & Ties & $115^{\mathrm{c}}$ & & & $\mathrm{Z}=-4.38^{\mathrm{d}}$ & $<0.0001$ \\
\hline & Total & 230 & & & & \\
\hline
\end{tabular}

${ }^{\mathrm{a}}$ Compliance $2016<$ Compliance 2015 ; ${ }^{\mathrm{b} C o m p l i a n c e ~} 2016>$ Compliance 2015; ${ }^{\mathrm{c} C o m p l i a n c e} 2016=$ Compliance 2015 ; ${ }^{\mathrm{d}}$ Based on positive ranks. 
Table 4. Pre-education vs. post-education HH compliance trends by profession.

\begin{tabular}{|c|c|c|c|c|c|c|c|c|c|c|c|c|c|}
\hline & \multicolumn{8}{|c|}{ Difference within profession } & \multicolumn{5}{|c|}{ Difference between profession } \\
\hline & \multicolumn{8}{|c|}{ HH compliance: post-education - pre-education } & \multicolumn{5}{|c|}{ HH compliance: post-education } \\
\hline \multicolumn{14}{|c|}{ Rank } \\
\hline Profession* & & $+\mathrm{ve}$ & & -ve & Ties & Total & $\begin{array}{c}\text { Test } \\
\text { statistic }\end{array}$ & $p$-value & Done & Not done & Total & $\begin{array}{c}\text { Test } \\
\text { statistic }\end{array}$ & $p$-value \\
\hline & $\mathrm{n}$ & Mean & $\mathrm{n}$ & Mean & & & & & & & & & \\
\hline Physicians & $43^{\mathrm{a}}$ & 30.0 & $16^{\mathrm{b}}$ & 30.0 & $44^{\mathrm{c}}$ & 103 & $\mathrm{Z}=-3.51^{\mathrm{d}}$ & $<0.0001$ & $72(69.9)$ & $31(30.1)$ & 103 & & \\
\hline Nurse & $32^{\mathrm{a}}$ & 24 & $15^{\mathrm{b}}$ & 24 & $64^{\mathrm{c}}$ & 111 & $\mathrm{Z}=-2.48^{\mathrm{d}}$ & $<0.013$ & $78(70.3)$ & $33(29.7)$ & 111 & $\chi^{2}(\mathrm{df} 2)=0.41$ & 0.81 \\
\hline Technician & $6^{\mathrm{a}}$ & 5 & $3^{\mathrm{b}}$ & 5 & $7^{\mathrm{c}}$ & 16 & $\mathrm{Z}=-1.0^{\mathrm{d}}$ & $<0.32$ & $10(62.2)$ & $6(37.8)$ & 16 & & \\
\hline Total & 81 & ---- & 34 & ---- & 115 & 230 & & & $160(69.6)$ & $70(30.4)$ & 230 & & \\
\hline
\end{tabular}

${ }^{\mathrm{a}}$ Compliance $2016<$ Compliance 2015; ${ }^{\mathrm{b} C o m p l i a n c e} 2016>$ Compliance 2015; ${ }^{\mathrm{c} C o m p l i a n c e} 2016$ = Compliance 2015; ${ }^{\mathrm{d} B a s e d}$ on positive ranks. ${ }^{\star}$ Number of $\mathrm{HH}$ actions done within a profession not the number of the individual HCWs in the profession.

Table 5. (a) Post-education (2016) HH compliance within individual departments; (b) Post-education (2016) HH compliance between departments. (Wilcoxon signed ranks test, related samples).

(a)

\begin{tabular}{|c|c|c|c|c|c|c|c|c|}
\hline & \multicolumn{8}{|c|}{ HH compliance: post-education - pre-education } \\
\hline & & & Rank & & & & & \\
\hline \multirow[b]{2}{*}{ Department } & \multicolumn{2}{|c|}{$+\mathrm{ve}$} & \multicolumn{2}{|c|}{$-\mathrm{ve}$} & \multirow[b]{2}{*}{ Ties } & \multirow[b]{2}{*}{ Total } & \multirow{2}{*}{$\begin{array}{c}\text { Test } \\
\text { statistic }\end{array}$} & \multirow[b]{2}{*}{$p$-value } \\
\hline & $\mathrm{n}$ & Mean & $\mathrm{n}$ & Mean & & & & \\
\hline $\mathrm{ER}(\mathrm{n}=24)$ & $7^{\mathrm{a}}$ & 7 & $6^{\mathrm{b}}$ & 7 & $11^{\mathrm{c}}$ & 24 & $\mathrm{Z}=-0.28^{\mathrm{d}}$ & 0.78 \\
\hline ICU & $12^{\mathrm{a}}$ & 11 & $9^{b}$ & 11 & $14^{\mathrm{c}}$ & 35 & $Z=0.65^{\mathrm{d}}$ & 0.51 \\
\hline Male ward & $15^{\mathrm{a}}$ & 10 & $4^{\mathrm{b}}$ & 10 & $28^{\mathrm{c}}$ & 47 & $\mathrm{Z}=-2.52^{\mathrm{d}}$ & 0.012 \\
\hline Female ward & $21^{\mathrm{a}}$ & 12.5 & $3^{\mathrm{b}}$ & 12.5 & $20^{c}$ & 44 & $\mathrm{Z}=-3.67^{\mathrm{d}}$ & $<0.0001$ \\
\hline NICU & $9^{a}$ & 6.5 & $3^{\mathrm{b}}$ & 6.5 & $14^{\mathrm{c}}$ & 26 & $\mathrm{Z}=-1.73^{\mathrm{d}}$ & 0.083 \\
\hline Pediatrics & $12^{\mathrm{a}}$ & 9.5 & $6^{\mathrm{b}}$ & 9.5 & $14^{\mathrm{c}}$ & 32 & $\mathrm{Z}=-1.41^{\mathrm{d}}$ & 0.15 \\
\hline Dental clinic & $5^{\mathrm{a}}$ & 4.5 & $3^{\mathrm{b}}$ & 4.5 & $14^{\mathrm{c}}$ & 22 & $\mathrm{Z}=-0.70^{\mathrm{d}}$ & 0.48 \\
\hline Total & 81 & --- & 34 & ---- & 115 & 230 & & \\
\hline
\end{tabular}

${ }^{\mathrm{a}}$ Compliance 2016 < Compliance 2015; ${ }^{\mathrm{b} C o m p l i a n c e} 2016$ > Compliance 2015; ${ }^{\mathrm{c} C o m p l i a n c e} 2016$ = Compliance 2015; ${ }^{\mathrm{d} B a s e d}$ on positive ranks.

(b)

\begin{tabular}{|c|c|c|c|c|c|}
\hline \multicolumn{6}{|c|}{ HH compliance: post-education } \\
\hline \multirow{2}{*}{ Department/unit } & Done & Not done & Total & \multirow{2}{*}{$\begin{array}{c}\text { Test } \\
\text { statistic }\end{array}$} & \multirow{2}{*}{$p$-value } \\
\hline & $\mathrm{n}(\%)$ & $\mathrm{n}(\%)$ & $\mathrm{n}(\%)$ & & \\
\hline ER & $10(41.7)$ & $14(58.3)$ & $24(100.0)$ & \multirow{8}{*}{$\chi^{2}(\mathrm{df} 6)=18.76$} & \multirow{8}{*}{0.005} \\
\hline ICU & $20(57.1)$ & $15(42.9)$ & $35(100.0)$ & & \\
\hline Male ward & $37(78.7)$ & $10(21.3)$ & $47(100.0)$ & & \\
\hline Female ward & $36(81.8)$ & $8(18.2)$ & $44(100.0)$ & & \\
\hline NICU & $21(80.8)$ & $5(19.2)$ & $26(100.0)$ & & \\
\hline Pediatrics & $20(62.5)$ & $12(37.5)$ & $32(100.0)$ & & \\
\hline Dental clinic & $16(72.7)$ & $6(27.3)$ & $22(100.0)$ & & \\
\hline Total & $160(69.6)$ & $70(30.4)$ & $230(100.0)$ & & \\
\hline
\end{tabular}




\section{Discussion}

An HCAI-free environment, mandates a prevailing sound HH culture of the healthcare facility's staff. By far, HH may well be the single most effective measure for reducing HCA rates to lowest possible [15] [16] [18] [19] [20] [30]. Such aim may only be achieved on a firm-ground $\mathrm{HH}$ assurance strategy implemented on an ongoing and timely-monitoring basis. In a study by Kirland and colleagues (2012) [31], the HCAI rate was reduced from 4.8 to 3.3/1000 inpatient day, after the implementation of a healthcare facility-wide HH strategy designed to improve the HCWs' HH behavior in a continuous basis. The WHO-sponsored $\mathrm{HH}$ multimodal strategy requires embracing certain interventional procedures, such as continuous $\mathrm{HH}$ education programs, and a suitable $\mathrm{HH}$ resource line, e.g., providing ABHRs all over the facility's floors and at all points of care [7]. A strong support and understanding from the facility's management would only render applying such strategy feasible. Meanwhile, the better structured and closely observed $\mathrm{HH}$ policy the higher compliance and sustainable $\mathrm{HH}$ practice [20] [32] [33]. On our part, the utilized WHO multimodal-based strategy was taken as a guidance to control and prevent cross-transmission of infection within WDH care environment. Findings from this research indicate that the change in the post-education compliance rate varied between low or insignificant-to satisfactory - up to high, including overall rates, compliance by the 5-moment indications, by profession and point of care, as well as $\mathrm{HH}$ action preference (HHW/HR). Such compliance pattern was more or less consistent with that have been found in literature.

Overall $H H$ compliance rate: In the pre-education phase, the HCWs' $\mathrm{HH}$ compliance was as low as $49.1 \%$. It seems that such low baseline compliance rate is a universal trend. Bukhari et al. (2011) in Saudi Arabia [27] reported a pre-training compliance rate as low as $50.3 \%$, close to ours. Al-Tawfiq, et al., (2013), [34] too found a country-wide overall pre-education compliance of $38 \%$, a rate to improve utilizing multifaceted $\mathrm{HH}$ approach. In the post-education phase, we achieved a satisfactory change in HCWs' compliance from $49.1 \%$ to 69.6\% past-training, [in which case, the study's objective of $\mathrm{HH}$ improvement was achieved, with a negligible difference (only $0.4 \%$ ) from the benchmark target 70\%]. In the study by Farhoudi et al. (2016) in Iran, [33] a sustainable improvement of $\mathrm{HH}$ practice of a HCWs' cohort admitted to a standardized $\mathrm{HH}$ improvement program was well maintained, with a notable increase of $\mathrm{HH}$ compliance rate from $51 \%$ to $67.2 \%$.

HH by the 5-moment indications. In our study, only the compliance after body fluid exposure (5-moment indication 3) significantly improved from 50\% up to $88.9 \%$, as well as the compliance after patient contact (5-moment indication 4) from $50.9 \%$ to $84.7 \%$. Most HH studies which have deployed standardized $\mathrm{HH}$ improvement strategies showed such partial compliance improvement in the 5-moment indications analyses. In Farhoudi et al. (2016), [33] experiment, the HCWs' observed HH response to "after body fluid exposure" mounted 50\% 
before the $\mathrm{HH}$ intervention but only $47.1 \%$ after the intervention. Other indications recorded an improvement in $\mathrm{HH}$ compliance trend with a variable a significance tendency. [33] In China, Shen and collaborates (2017) [35] also reported a partial improvement in the 5-moment $\mathrm{HH}$ indications response, e.g., an insignificant difference both after body fluid exposure (5-moment indication 3) (77.4\% and $82.3 \%, p<0.05$ ), and touching patient surroundings (5-moment indication 5) $(79.0 \%$ and $81.7 \%, p<0.05)$, while other indications were met with a significant $\mathrm{HH}$ improvement tendency.

HH by profession: Hand hygiene compliance trend may vary by the HCW's individual professions. [29] [30] In our study, physicians and nurses, but not care providing technicians/auxiliary staff could achieve a significant improvement in their $\mathrm{HH}$ behavior as a result of joining the $\mathrm{HH}$ education program. On the other hand, the high $\mathrm{HH}$ compliance as observed during the post-education period uniformly persisted almost among all profession groups (did not statistically differ) (nurses $70.3 \%$, physicians $69.9 \%$, and technicians/auxiliary staff $62.2 \%, p>0.05)$. Other studies reported a significantly different $\mathrm{HH}$ compliance rates between HCWs who had submitted to standardized HH education programs, e.g., a $\mathrm{HH}$ compliance rate of $82.4 \%$ for physician vs. $72.7 \%$ for nurses. [33] The Chinese experiment also reported a $\mathrm{HH}$ compliance rate improvement in the post-education period of $84.04 \%$ among physicians, $81.07 \%$ among nurses, and 69.4\% among other professions. [35] Examining tertiary-care hospital compliance among HCWs who had been admitted to 1-year multimodal HH intervention program, Chavali et al. (2014) [32] in India found that only $63 \%$ of nurses adhered to $\mathrm{HH}$ performance, e.g., compared to $86.5 \%$ of the hospital's allied staff [32].

$H H$ by department/unit. In our study, only in male -and female wards showed a significant improvement in the $\mathrm{HH}$ compliance trend as a result of the education plan. Unlike the $\mathrm{HH}$ performance among professions during the post-education period, the departments/units significantly varied in their $\mathrm{HH}$ compliance as observed during that period, e.g., female and male wards and NICU recorded maximum compliance rate ranging between $78.7 \%-81.8 \%$. The compliance in our ICU reached only $57.1 \%$ vs. $42.9 \%$ non-compliance rate, despite the HH education. In the study by Alsubaie S, et al. [12] to identify baseline determinants of $\mathrm{HH}$ compliance among $242 \mathrm{HCWs}$ observed at the University Hospital in Riyadh, KSA, an overall 58\% non-compliance rate in all five ICUs was reported. Being a physician and an allied health professional, as in our study, were significant non-compliance correlates. On the other hand, Al-Dorzi, et al. (2014) [25] revealed an overall baseline compliance of 64\%, (which was lowest at night-than day shifts) at the observed ICU of a tertiary care hospital in Riyadh, KSA. The compliance improved to $>80 \%$ after implementing a stepwise multifaceted and resourceful approach that included extensive education, comprehensive $\mathrm{HH}$ promotion material, active feedback and later universal contact precautions. 
How far was the HH improvement achieved? The level for compliance with recommended $\mathrm{HH}$ techniques often varies between healthcare organizations; based on the quality and patient safety policy in place and the particular phases of the healthcare system's development. For instance, a national benchmark level of $\mathrm{HH}$ compliance among HCWs in Manitoba, Canada, was set at $70 \%$ in 2015-2016 and was increased to $75 \%$ in $2016-2017$ until it reached $80 \%$ in 2017-2018 [36]. In India, Chavali et al. (2014) [32] reported an overall 78\% compliance among the studied HCWs, a rate which was below the $90 \%$ benchmark level in critical care areas. There was also a significant predominance of HR over HW among staff ( $58.2 \%$ vs. $41.8 \%)$ during the post-education era. In practice, if the hands are not visibly soiled, HR is perceived by many HCWs as more practical and less time consuming than HW, meanwhile giving the same sanitizing effect. (For instance, HR for 15 seconds was found not inferior to 30 seconds in reducing bacterial counts on hands under the described experimental conditions) [37]. The higher tendency for HR among HCW populations was shown to be the favored way of $\mathrm{HH}$, after intervention in the majority of points of care observed [20].

Limitations and strengths. The study scale may have been limited by the number of the observing team members, given the limited ability, e.g., to recruit some of the hospital's staff and train them to join the observation team. Having the adequate number of observers, especially at critical areas, such as the ICU, helps alleviate the remarkable non-compliance rate at such critical care point. Otherwise, the study had several strengths, adding to the findings validity and generalizability potential. First, the overall target set for $\mathrm{HH}$ improvement (70\%) was almost accomplished (69.6\%). The study adopted rigorous WHO multimodal strategy in establishing the $\mathrm{HH}$ project, the impact of which upon improving HH behavior among HCWs is evident. The direct observation method not only stands as a superior $\mathrm{HH}$ follow-up tool in the healthcare arena, but it can both determine the compliance with all 5 moments of $\mathrm{HH}$ and evaluate $\mathrm{HH}$ technique and check compliance rates according to the HCWs [31] [38].

\section{Conclusion}

The study aim has been achieved, using the selected study design and implementing the WHO multimodal strategy in WDH. With the intervention applied, HH compliance significantly improved. Moreover, the benchmark level (70\%) for $\mathrm{HH}$ compliance among our HCWs was achieved. With the available resources to monitor HH adherence among WDH staff, direct observation remains our gold standard. As planned, further improvement to reach the $80 \%$ benchmark level for $\mathrm{HH}$ after the initial post-education year is underway. Important care areas, such as the ICU would be stressed upon to lift-up the low compliance observed in such critical point of care. A sustainable and sound $\mathrm{HH}$ behavior of WDH staff requires engaging each staff member in the training, so that a timely and correct $\mathrm{HH}$ becomes a genuine component of the quality im- 
provement and safety culture of WDH personnel. As such, a multifaceted approach advocating a diversity of educational methods for a wider coverage and a better compliance, as well as an effective feedback to relate the observation outcome both to staff and WDH authority are recommended.

\section{Conflicts of Interest}

The authors declare no conflicts of interest regarding the publication of this paper.

\section{References}

[1] World Health Organization (WHO) Clean Care Is Safer Care. The Burden of Health Care-Associated Infection Worldwide.

https://www.who.int/gpsc/country_work/burden_hcai/en/

[2] Allegranzi, B., Bagheri Nejad, S., Combescure, C., Graafmans, W., Attar, H., Donaldson, L., et al. (2011) Burden of Endemic Health-Care-Associated Infection in Developing Countries: Systematic Review and Meta-Analysis. The Lancet, 377, 228-241. https://doi.org/10.1016/S0140-6736(10)61458-4

[3] World Health Organization (WHO) (2013) The Burden of Health Care-Associated Infection Worldwide. A Summary. http://www.who.int/gpsc/country_work/summary_20100430_en.pdf

[4] Jia, H., Hou, T., Li, W., Ma, Q., Liu, W., Yang, Y., et al. (2016) Economic Loss Due to Healthcare-Associated Infection in 68 General Hospitals in China. Chinese Journal of Infection Control, 15, 637-641.

[5] Graves, N., Weinhold, D., Tong, E., Birrell, F., Doidge, S., Ramritu, P., et al. (2007) Effect of Healthcare-Acquired Infection on Length of Hospital Stay and Cost. Infection Control \& Hospital Epidemiology, 28, 280-292. https://doi.org/10.1086/512642

[6] European Centre for Disease Prevention and Control (ECDPC) (2018) Healthcare-Associated Infections.

https://ecdc.europa.eu/en/healthcare-associated-infections

[7] Allegranzi, B. and Pittet, D. (2009) Role of Hand Hygiene in Healthcare-Associated Infection Prevention. Journal of Hospital Infection, 73, 305-315. https://doi.org/10.1016/j.jhin.2009.04.019

[8] Weber, D.J., Anderson, D. and Rutala, W.A. (2013) The Role of the Surface Environment in Healthcare-Associated Infections. Current Opinion in Infectious Diseases, 26, 338-344. https://doi.org/10.1097/QCO.0b013e3283630f04

[9] Erasmus, V., Daha, T.J., Brug, H., et al. (2010) Systematic Review of Studies on Compliance with Hand Hygiene Guidelines in Hospital Care. Infection Control and Hospital Epidemiology, 31, 283-294. https://doi.org/10.1086/650451

[10] Lee, A., Chalfine, A., Daikos, G.L., et al. (2011) Hand Hygiene Practices and Adherence Determinants in Surgical Wards across Europe and Israel: A Multicenter Observational Study. American Journal of Infection Control, 39, 517-520. https://doi.org/10.1016/j.ajic.2010.09.007

[11] Pittet, D., Hugonnet, S., Harbarth, S., et al. (2000) Effectiveness of a Hospital-Wide Programme to Improve Compliance with Hand Hygiene. The Lancet, 356, $1307-$ 1312. https://doi.org/10.1016/S0140-6736(00)02814-2

[12] Alsubaie, S., Maither, A.B., Alalmaei, W., Al-Shammari, A.D., Tashkandi, M., Somily, A.M., et al. (2013) Determinants of Hand Hygiene Noncompliance in Inten- 
sive Care Units. American Journal of Infection Control, 41, 131-135. https://doi.org/10.1016/j.ajic.2012.02.035

[13] Mahfouz, A.A., El Gamal, M.N. and Al-Azraqi, T.A. (2013) Hand Hygiene NonCompliance among Intensive Care Unit Health Care Workers in Aseer Central Hospital, South-Western Saudi Arabia. International Journal of Infectious Diseases, 17, e729-e732. https://doi.org/10.1016/j.ijid.2013.02.025

[14] Pittet, D. and Boyce, J.M. (2001) Hand Hygiene and Patient Care: Pursuing the Semmelweis Legacy. The Lancet Infectious Diseases, 1, 9-20. https://doi.org/10.1016/S1473-3099(09)70295-6

[15] World Health Organization (WHO) WHO Guidelines on Hand Hygiene in Health Care. The First Global Patient Safety Challenge: "Clean Care is Safer Care". http://apps.who.int/iris/bitstream/handle/10665/44102/9789241597906_eng.pdf?seq uence $=1 \& u a=1$ https://www.who.int/gpsc/clean_care_is_safer_care/en/

[16] World Health Organization (WHO) A Guide to the Implementation of the WHO Multimodal Hand Hygiene Improvement Strategy. WHO, Geneva.

[17] World Health Organization (WHO) (2009) Hand Hygiene Technical Reference Manual. World Health Organization, Geneva.

http://www.who.int/gpsc/5may/tools/evaluation_feedback/en/index.html

[18] Sax, H., Allegranzi, B., Chraïti, M.N., Boyce, J., Larson, E. and Pittet, D. (2009) The World Health Organization Hand Hygiene Observation Method. American Journal of Infection Control, 37, 827-834. https://doi.org/10.1016/j.ajic.2009.07.003

[19] Clean Care Is Safer Care. About SAVE LIVES: Clean Your Hands. https://www.who.int/gpsc/5may/background/5moments/en/

[20] Allegranzi, B., Gayet-Ageron, A., Damani, N., Bengaly, L., McLaws, M.L., Moro, M.L., et al. (2013) Global Implementation of WHO's Multimodal Strategy for Improvement of Hand Hygiene: A Quasi-Experimental Study. The Lancet Infectious Diseases, 13, 843-851. https://doi.org/10.1016/S1473-3099(13)70163-4

[21] Arntz, P.R., Hopman, J., Nillesen, M., Yalcin, E., Bleeker-Rovers, C.P., Voss, A., et al. (2016) Effectiveness of a Multimodal Hand Hygiene Improvement Strategy in the Emergency Department. American Journal of Infection Control, 44, 1203-1207. https://doi.org/10.1016/j.ajic.2016.03.017

[22] Stewardson, A.J., Sax, H., Gayet-Ageron, A., Touveneau, S., Longtin, Y., Zingg, W., et al. (2016) Enhanced Performance Feedback and Patient Participation to Improve Hand Hygiene Compliance of Health-Care Workers in the Setting of Established Multimodal Promotion: A Single-Centre, Cluster Randomised Controlled Trial. Lancet Infectious Diseases, 16, 1345-1355. https://doi.org/10.1016/S1473-3099(16)30256-0

[23] Pfafflin, F., Tufa, T.B., Getachew, M., Nigussie, T., Schonfeld, A., Haussinger, D., et al. (2017) Implementation of the WHO Multimodal Hand Hygiene Improvement Strategy in a University Hospital in Central Ethiopia. Antimicrobial Resistance \& Infection Control, 6, 3. https://doi.org/10.1186/s13756-016-0165-9

[24] Mahfouz, A.A., Al-Zaydani, I.A., Abdelaziz, A.O., El-Gamal, M.N. and Assiri, A.M. (2014) Changes in Hand Hygiene Compliance after a Multimodal Intervention among Health-Care Workers from Intensive Care Units in Southwestern Saudi Arabia. Journal of Epidemiology and Global Health, 4, 315-321. https://doi.org/10.1016/j.jegh.2014.05.002

[25] Al-Dorzi, H.M., Matroud, A., Al Attas, K.A., Azzam, A.I., Musned, A., Naidu, B., et al. (2014) A Multifaceted Approach to Improve Hand Hygiene Practices in the Adult Intensive Care Unit of a Tertiary-Care Center. Journal of Infection and Public 
Health, 7, 360-364. https://doi.org/10.1016/j.jiph.2014.02.003

[26] AlNakhli, D.J., Baig, K., Goh, A., Sandokji, H. and Din, S.S. (2014) Determinants of Hand Hygiene Non-Compliance in a Cardiac Center in Saudi Arabia. Saudi Medical Journal, 35, 147-152.

[27] Bukhari, S., Hussain, W.M., Banjar, A., Almaimani, W.H., Karima, T.M. and Fatani, M.I. (2009) Hand Hygiene Compliance Rate among Healthcare Professionals. Saudi Medical Journal, 32, 515-519.

[28] Department of Health, Australia. Northern Territory Government. Hand Hygiene Compliance Rate Key Performance Indicators 2017/18. https://digitallibrary.health.nt.gov.au/prodjspui/bitstream/10137/7007/1/Hand\%20 Hygiene\%20Compliance\%20Rate\%20KPI\%20Attribute\%20Sheet.pdf

[29] Huis, A., Schoonhoven, L., Grol, R., Donders, R., Hulscher, M. and van Achterberg, T. (2013) Impact of a Team and Leaders-Directed Strategy to Improve Nurses' Adherence to Hand Hygiene Guidelines: A Cluster Randomised Trial. International Journal of Nursing Studies, 50, 464-474. https://doi.org/10.1016/j.ijnurstu.2012.08.004

[30] Kretzer, E.K. and Larson, E.L. (1998) Behavioral Interventions to Improve Infection Control Practices. American Journal of Infection Control, 26, 245-253. https://doi.org/10.1016/S0196-6553(98)80008-4

[31] Kirkland, K.B., Homa, K.A., Lasky, R.A., Ptak, J.A., Taylor, E.A. and Splaine, M.E. (2012) Impact of a Hospital-Wide Hand Hygiene Initiative on Healthcare-Associated Infections: Results of an Interrupted Time Series. BMJ Quality \& Safety, 21, 10191026. https://doi.org/10.1136/bmjqs-2012-000800

[32] Chavali, S., Menon, V. and Shukla, U. (2014) Hand Hygiene Compliance among Healthcare Workers in an Accredited Tertiary Care Hospital. Indian Journal of Critical Care Medicine, 18, 689-693. https://doi.org/10.4103/0972-5229.142179

[33] Farhoudi, F., Sanaei Dashti, A., Hoshangi, D.M., Ghalebi, N., Sajadi, G. and Taghizadeh, R. (2016) Impact of WHO Hand Hygiene Improvement Program Implementation: A Quasi-Experimental Trial. BioMed Research International, 2016, Article ID: 7026169. https://doi.org/10.1155/2016/7026169

[34] Al-Tawfiq, J.A., Abed, M.S., Al-Yami, N. and Birrer, R.B. (2013) Promoting and Sustaining a Hospital-Wide, Multifaceted Hand Hygiene Program Resulted in Significant Reduction in Health Care-Associated Infections. American Journal of Infection Control, 41, 482-486. https://doi.org/10.1155/2016/7026169

[35] Shen, L., Wang, X., An, J., An, J., Zhou, N., Sun, L., et al. (2017) Implementation of WHO Multimodal Strategy for Improvement of Hand Hygiene: A Quasi-Experimental Study in a Traditional Chinese Medicine Hospital in Xi'an, China. Antimicrobial Resistance \& Infection Control, 6, 98.

https://doi.org/10.1186/s13756-017-0254-4

[36] Winnipeg Regional Health Authority (WRHA) Hand Hygiene Compliance. http://www.wrha.mb.ca/prog/ipc/hand-hygiene.php

[37] Pires, D., Soule, H., Bellissimo-Rodrigues, F., Gayet-Ageron, A. and Pittet, D. (2017) Hand Hygiene with Alcohol-Based Hand Rub: How Long Is Long Enough? Infection Control \& Hospital Epidemiology, 38, 547-552.

https://doi.org/10.1017/ice.2017.25

[38] Stewardson, A. and Pittet, D. (2011) Quicker, Easier, and Cheaper? The Promise of Automated Hand Hygiene Monitoring. Infection Control \& Hospital Epidemiology, 32, 1029-1031. https://doi.org/10.1086/662023 